\title{
Study on Physical Education Curriculum System Optimization Based on Health and Human Capital Theory
}

\author{
Jingqiang Wang \\ Business College of Hubei University of Technology \\ Wuhan, Hubei, 430070 \\ E-mail: 75154410@qq.com
}

\author{
Hewang Liu \\ Sport Department of Huazhong Agricultural University \\ Wuhan, Hubei, 430070 \\ E-mail: 49272499@qq.com
}

\begin{abstract}
This paper uses induction and deduction, comprehensive analysis method, based on the present of physical education in Chinese college, analyzes actual problems of college physical course system and takes "improve undergraduate's health human capital level " as guiding ideology to optimize college physical course system and proposes (1) from the point of improving undergraduate's health human capital level to optimize the course sequence of college physical course system, adjust content structure and proportion to make the course system more scientific and reasonable and provide basic support for improving quality of college physical teaching;(2) Centered on teaching, improve the evaluation regulation and index system, perfect evaluation mechanism and standards of quality assessment on the fair, scientific and different level. (3) Establish physical teaching department, health care department, student affairs department and linkage system to reduce the communication link, achieve the information exchange of student's health, mental condition and group activities, then build the "great sport" model, therefore add the proposals of improving work efficiency of college physical teaching and provide intelligence support for reform of sports teaching in college.
\end{abstract}

Keywords-health human resource capital; physical course system; linkage system

\section{THE QUESTION}

\section{A. Analysis of the present of China college physical course system}

The reforming and opening lasting for 35 years in China bring great economic prosperity, but as productivity structure changed dramatically and the mainstream shocked by foreign thoughts, relevant problems occur and college students are affected to some extent, shown as: weak character, low moral level, fitness level decline and unscientific life style ${ }^{[1]}$. The reality put forward new requirements for China physical education system: how to reform under current conditions to resist the bad effects. Scanning the present of China physical

In this paper, the basic research activities for the Central Universities special(Name: Social transformation of human capital to enhance the level of college health security system and path selection, Item Number: 2013RW012) Initial results of Hubei Provincial Department of Education issues (Name: Study on PE Curriculum System Optimization Based on Health and Human Capital Theory, Item Number: 2013179) course system (in view of limitation of study area, the paper just analyzes China college physical course system), there are primarily three problems: first, the direction of educational reform and educational purpose are not clear; Second, physical course system is not systematic and scientific; Third, college teaching quality evaluation system has strong subjectivity, evaluation index is not reasonable, teaching quality of teachers and study effects of students can't be assessed objectively and correctly ${ }^{[2]}$. The seriousness of these problems has valued by Center of CPC, Education Department, managers in college and frontline teachers, the reform of college physical course system is extremely urgent.

\section{B. The interpretation of Health Human Capital Theory}

Health Human Capital Theory originates from the theory of human capital in the field of economics. Mushkin (in 1962) is the first to come up with the concept of health human capital, which gradually develops as Health Human Capital Theory focusing on "investment and performance". Human capital is categorized into four forms: health, education, training and migration, among which health human capital is the carrier of the other 3 forms of human capital and plays the most crucial role in achieving the efficacy of human capital. The improvement of health human capital should be based on the coactions among scientific lifestyle, good psychological and moral quality, and physical quality ${ }^{[3]}$. This proves that physical quality has inner relation with health human capital. In addition, it is the component of health human capital. Therefore, by developing college students' health human capital, we could directly improve their physical quality. Furthermore, under the current condition in China, it is more in line with the goal and demand of "to advance from a human capital giant to a human capital power", and also, it provides possibility for taking 'developing college students' health human capital' as the guiding thought of optimizing college's physical course system.

\section{ANALYSIS OF THE PROBLEM}

\section{A. Analysis of the teaching reform direction and the teaching goal which is not clear}

The direction and the goal are fundamental to guide practice. Since "Deepen the theoretical basis of the curriculum 
reform" published by Lvda in 2001, the door to Chinese education in basic research on theoretical is open. Since then, Chinese college physical education has also launched 8 reforms and discussion, but the effect of the university sports education is always difficult to make the social satisfied. The fundamental reason is that the guiding ideology is not clear, resulting in that the reform direction is biased and teaching goal is lost. The "national long-term education reform and development plan (2010-2020 year)"which is examined and adopted by China State Council executive meeting In 2010 May, clearly stress that "Strengthen the sports, firmly establish the idea of health first. Strengthen the mental health education to promote student health, physically fit, strong-willed" and define the problem of the sports teaching guiding ideology of physical education and the view of "Health First" has also been generally recognized. However, in practice, from the management department to the sports teachers focus the sports teaching on the "development of students' physical quality". This separation of the guiding ideology and specific practice result in the chaos of the university sports teaching curriculum system, and eventually lead to low quality of college physical education.

Health human capital theory thinks that the improvement of the human capital health level must play role with the scientific way of life, good mental and moral qualities and physical qualities. The college students already have basic theoretical knowledge, analytical skills, self-control, the prototype of life and morality and have the conditions to develop healthy levels of human capital with the help of college teachers.

\section{B. Analysis of PE curriculum system that lacks systematic and scientific}

Physical education is an integral part of basic education which should follow the basic law of education; however, the physical education curriculum also has the characteristics of open teaching environment and high risk coefficient of injury accident. The dominant physical education curriculum and hidden curriculum concentric pattern relatively outstanding features of their own, PE curriculum system should also be in accordance with its own characteristics, and comprise in accordance with systematic, scientific requirements. However, the Chinese university PE curriculum system after eight major reforms has made great progress, but there are still some outstanding problems: emphasis on technical training to teach but ignore interest, emphasis on classroom paradigm but ignore teaching atmosphere, emphasis on sports subjects but ignore practical exercise, emphasis on the structural integrity of the knowledge sector but ignore the real needs. Especially nowadays many colleges and universities using a three autonomous mode---"self-select the item content, choose classroom teachers, choose class time," in order to meet the autonomy of student course, resulting in ignoring the teaching content. It makes rigidly uniform to defining PE curriculum teaching time, teaching methods, assessment methods, and this form of unification of serious violations of the law of project at physical education, breaking the system of physical education curriculum system.
C. The evaluation system of teaching quality of physical education in Colleges and universities is strong subjective and its evaluation index is not reasonable, which can not objectively and accurately evaluate teachers' teaching quality and analysis the learning effect

Sports teaching quality evaluation system is based on the physical education goals and standards, using qualitative and quantitative analysis method to measure the physical teaching process and effect, and give the content system of value judgment. In a broad sense, the teaching quality evaluation system of college physical education should be a part of the university sports curriculum system. Its construction is reasonable or not and the quality evaluation of the implementation is good or not will have a direct impact on the process and quality of construction and teaching practice of college sports curriculum system. Today, the current PE teaching quality evaluation system in the quality control aspect appears in the system level, but the operating effect is poor. Due to the multi dimension structure of school physical education department and the diverse needs of social service function, the center position of physical education of school physical education department is seriously impacted. And in the actual process of evaluation, some phenomenon appears: supervision is oversee and guidance is insufficient; and too rigid requirements for teachers, lack of caring people; teaching evaluation is too subjective, lack of objectivity; the evaluation index is unified, lack of targeted. Although the teaching is emphasized the first in all types of documents at all levels, in the actual operation, however, due to the weak position of physical education and function divisions, too much attention is paid to the PE teachers' scientific research work and carry out the monitoring and evaluation of teaching quality from the school level. The teaching quality evaluation system of self constraint mechanism of the teaching quality and standardized, systematic, complete system is less involved, which is inclined to qualitatively describe the overall teaching quality evaluation, less quantitative study, the lack of evaluation system of operational. This separation of the management and practice of teaching practice result in that the sports management is lack of scientific assessment, so classroom teachers' work is chaos.

\section{CONCLUSION AND RECOMMENDATION}

\section{A. Regard "The development of College Students' health level of human capital" as the guiding ideology of the optimization of college physical education curriculum system}

Regarding "The development of College Students' health level of human capital" as the optimization of college physical education curriculum system, the guiding ideology of College sports' reform not only can achieve the target-- "to improve the physical quality of the students", but also can get the health knowledge, students' health attitudes and health behavior together, expanding the concept of Physical Education. This "new education concept expanded should allow everyone to play and enhance their creative potential, should also help to dig out the hidden in each of us wealth", so as to improve the efficiency of health. From the national macro level, it can provide the basic support for the target which is China is from 
the human capital power to the power of human capital. From the physical education, it can make the public sports teaching have a definite object in view, and make the purpose stronger, allocation of resources more efficient, so as to improve the effect of teaching.

\section{B. Follow the rules; optimize the college physical education curriculum sequence}

In the physical education curriculum, teaching rules of different projects, knowledge and skills are different. Teaching process should also follow the rules of reasonable arrangement. We must proceed from the course sequence, respect teaching knowledge module, project content and skill content, and optimize curriculum sequence, so as to make the university sports curriculum system more reasonable and scientific.

\section{According to the actual demand, adjust the structure and proportion of college sports curriculum content}

Basing on the school sports resources, fitness knowledge, skills learning rule and the characteristics of the project itself and the actual demand of improving college sports curriculum, intensify the construction of college sports curriculum multimedia network teaching platform for interaction, extend the learning time of part periodic longer project, adjust the structure and proportion of curriculum contents and reduce the proportion of sports skills, increase the proportion of positive impact of exercise on physiological function, exercise and nutrition interventions integrated knowledge, science lifestyle theoretical knowledge and skills. The original scattered knowledge and skills in college students' individual can be integrated.

\section{In the sports teaching as the center, perfect the evaluation system of College Physical Education Teaching Quality}

Physical education teachers undertake not only the development of students' physical quality, cultivation of good sports spirit, enriching the students' sports skills, developing the habit of physical exercise, improving their health level of human capital and other tasks, but also are responsible for campus sports and cultural prosperity of the school, afterschool sports organizations, opening of school sports and other outreach mission. It is already under full load requirements for Physical Education department with small team of teachers, lack of resources possession, and social status bias. When assessing the quality of Physical Education, we should first establish a "sports teaching center" guiding ideology, and distribute the scientific research evaluation index according to the characteristics of PE Teachers. We should perfect the evaluation system and index system from the equity (fairness design evaluation process, the evaluation process, the evaluation results of transparent public), science (the assessment team is involving teaching management, subject experts, teachers and students and other stakeholders, validity of test evaluation indexes for the scientific evaluation index system), difference (according to the different types and locations of different colleges and the teachers) level. At the same time, we should combine with teaching quality random or periodic evaluation of various academic organizations, establish the related sports teaching evaluation from the third party organization, evaluate physical education teaching quality and improve the collaborative evaluation system and the evaluation standard of quality through the media organization in digital for.

\section{E. Set up the Multi-agency linkage mechanism with studies department, health department, education department}

The school department and medical department hold a lot of students' activity information and physical health information and physical education department is responsible for the students' physical health counseling and training. From the promotion of College Students' health human capital level three should be unified. Setting up the Multi-agency linkage mechanism with studies department, health department, education department can save work cost, smooth communication links, make the information exchange such as students' mental health, physical fitness and group activities, and construct the "Big Sports" model, to improve the work efficiency of College Physical Education teaching.

\section{REFERENCES}

[1] Chinese Students' Constitution and Health Research Group, The Chinese Students' Constitution and Health Survey Report of 2010 [M] Beijing: Higher Education Press, 2012:75-77.

[2] Wang Jian, Pan Lingyun, Reality Inquire and Development Path of School Physical Education Who Learn under the Horizon [J], Sports Science 2013,33 (11): 17-27.

[3] Schultz, Human Capital Investment [M], Beijing Economic Institute Press 1990: 3 .

[4] Gao Si, The Major Initiatives of Improving the Quality of Undergraduate Teaching [J], Teaching of Chinese University, 1990:3.

[5] Liu Hewang, Liu Mingchang, The Causation and Risk Response of School Sports Injury Accident [J], Sports Adult Education 2011(2):29-30.

[6] Li Zhi, Discussion of College Sports Teaching Quality Evaluation System [J], Education and Career, 2009(36):183.

[7] Tian Wenxue, Analysis of Current Situation of College Physical Education Quality Assessment [J], Sports Science,2013,36(6):107-110.

[8] International Committee of the 21st Century Education, Education - The Treasure Within [M], translated by Chinese Language Department of UNESCO Headquarters, Beijing, Education Science Press, 1996:76.

[9] Cui Ruixue, Research on the Relationship between Physical Resources and the Physical Education Curriculum Reform Programs [J], Education Exploration 2010, (2):55-56. 